\title{
MELHORIA DE PROCESSOS NA GESTÃO PÚBLICA: UMA PESQUISA-AÇÃO COM FOCO NAS ATIVIDADES ADMINISTRATIVAS DE UM PROGRAMA DE INTERCÂMBIO ESTUDANTIL DE UMA UNIVERSIDADE PÚBLICA
}

\section{PROCESS IMPROVEMENT ON PUBLIC ADMINISTRATION: AN ACTION RESEARCH FOCUSING ON ADMINSTRATIVE ACTIVITIES OF STUDENT MOBILITY PROGRAM OF A BRAZILIAN PUBLIC UNIVERSITY}

\author{
Sanderson César Macêdo Barbalho* E-mail: sandersoncesar@unb.br \\ Maria Cristina Mozaner Nitzsche ** E-mail: crisnit2016@gmail.com \\ Ananda Silveira Dantas* E-mail: ananda.sd2@gmail.com \\ *Universidade de Brasília (UNB), Brasília, DF \\ ${ }^{* *}$ Centro Universitário de Araraquara (UNIARA), Araraquara, SP
}

Resumo: $O$ presente artigo apresenta o estudo e proposição de melhorias dos processos administrativos de um programa de mobilidade estudantil em uma Instituição Federal de Ensino Superior. Foi realizada uma pesquisa-ação através do mapeamento dos processos utilizando fluxograma de processo e foram identificados pontos de melhoria baseados em conceitos de produção enxuta. Os procedimentos metodológicos utilizados foram análise de documentos pertencentes ao Programa e análise do histórico dos documentos e ações desenvolvidos no setor por ele responsável. É realizado o desenho e descrição do macroprocesso. Posteriormente foi realizada análise dos desperdícios do processo atual e são propostas ações de melhoria com base em mapas de estado futuro. Propôs-se eliminar atividades que geravam desperdício e que não agregavam valor. Tais propostas foram validadas com os gestores do Programa e algumas iniciativas foram implementadas. Melhorias da ordem de $74 \%$ no fluxo de informações e $44 \%$ nos tempos de processamento foram conseguidas.

Palavras-chave: Melhoria de processos. Produção Enxuta. Programa de mobilidade estudantil.

Abstract: This paper presents the study and proposition of improvements in administrative processes of a student mobility program in a Federal Institution of Higher Education. This investigation is an action research for mapping the processes through process flow charts and identifying points for improvement based on Lean manufacturing concepts. The methodological procedures used were analysis of documents related to the Program and analysis of historical documents and actions developed in the sector responsible for it. The research carried out the design and description of the macro process. Analysis of the waste is made of the current process and are proposed improvement actions based on future state maps. It proposed to eliminate activities that generated waste and that did not add value. Such proposals have been validated with the managers of the program and some initiatives have been implemented. Improvements up to $74 \%$ in the information flow and $44 \%$ in the processing times were achieved.

Keywords: Process improvement. Lean Manufacturing. Student mobility program. 


\section{INTRODUÇÃO}

O presente artigo relata a proposição de melhorias nos processos administrativos de um Programa de intercâmbio estudantil internacional em uma Instituição Pública Federal de ensino superior, baseada em conceitos de melhoria de processos e de produção enxuta.

Sabe-se que qualquer operação produz bens ou serviços, ou um misto dos dois e faz isso por um processo de transformação. Para Gonçalves (2000b), os processos na área fabril são fáceis de observar e o desperdício e o retrabalho são claramente identificáveis, mas no âmbito dos serviços impera a dificuldade de identificação dos processos e de suas possibilidades de melhoria.

A Universidade Federal que é objeto da pesquisa realizada adota a mobilidade como uma das formas de sua internacionalização. A mobilidade internacional no ensino possibilita um conhecimento maior da área de atuação de quem a está realizando. Além do conteúdo estudado em si, o estudante vivenciará novas culturas, formas de aprendizado e de avaliação de diferentes sistemas de ensino etc. (TELES, 2005).

Atualmente, o tema da mobilidade estudantil está muito evidente em função do destaque dado ao Programa Ciência sem Fronteiras (CsF). É importante mencionar que a área pesquisada neste trabalho também atuava no CsF, porém o caráter permanente e o maior tempo de funcionamento do Programa ESCALA Estudantil (PEE) da Associação de Universidades Grupo Montevidéu (AUGM), ou PEE-AUGM, contribuíram para que ele fosse escolhido como piloto para a melhoria de processos aqui relatada.

A metodologia utilizada no estudo foi pesquisa-ação, na qual o participante e os usuários atuam em conjunto com ações que visam contribuir com uma dada realidade na busca de superação de seus entraves (THIOLENT, 1997; COUGHLAN e COGHLAN, 2002). Há que se mencionar que o referido Programa não contava com processos sistematizados e padronizados no início do estudo aqui relatado, mas operava em formato ad hoc, o que implicou que a mera análise e modelagem do processo contribuíram para explicitar elementos a serem mais bem trabalhados e racionalizados. $O$ trabalho foi realizado nas etapas assim sumarizadas: (1) mapear 
os atuais processos utilizados no Programa; (2) avaliar os processos atuais utilizando conceitos do Lean Office; e (3) identificar e propor melhorias que pudessem contribuir para padronizar as operações dos processos utilizados no Programa. O detalhamento da metodologia empregada no trabalho é apresentado em seção específica.

Enfim, este artigo está organizado nas seguintes seções: referencial teórico, apresentação do objeto de estudo, o procedimento de coleta de dados para o mapeamento dos macroprocessos relacionados ao Programa, os resultados da análise dos dados com a proposta das melhorias, uma análise de indicadores de desempenho do processo após as melhorias e as considerações finais.

\section{REFERENCIAL TEÓRICO}

\subsection{Gestão por processos}

Segundo Davenport (1994, p. 1) "as atividades empresariais devem ser vistas não em termos de funções, departamentos ou produtos, mas de processos-chave". Para Gonçalves (2000b) "... os processos podem ser agregados em macroprocessos e subdivididos em subprocessos ou grupos de atividades, e o nível de agregação mais adequado depende do tipo de análise que se pretende fazer...". Gonçalves (2000a) considera que as pessoas, no geral, têm dificuldade de enxergar uma organização por processos - que é uma visão voltada para o cliente externo - e maior probabilidade de incorporarem uma visão voltada para a estrutura interna departamentos e áreas funcionais.

Para Krajewski et al. (2009), uma vez que um processo é realmente entendido, ele pode ser melhorado sendo o mapeamento dos processos utilizado com o objetivo de identificar pontos de melhoria. Segundo Gonçalves (2000a), mapear um processo permite identificar e aperfeiçoar as interfaces funcionais que são os pontos onde o trabalho é transferido para a próxima unidade organizacional e onde mais se gera retrabalho e gargalos.

Os processos podem ser categorizados de três formas (DAVENPORT, 1994; GONÇALVES, 2000b): processos de negócio (caracterizam a atuação da empresa e 
são suportados por outros processos internos), processos organizacionais (centralizados na organização e viabilizam o funcionamento dos subsistemas) e processos gerenciais (focados nos gerentes, incluindo atividades de medição e ajuste de desempenho). Ultimamente, o Corpo Comum de Conhecimentos em Gestão de Processos de Negócio (BPM CBOK - Business Process Management Common Body of Knowledge - ASSOCIATION..., 2013) tem atuado na homogeneização dos conceitos vinculados à gestão por processos, tendo denominado os tipos de processos como primários, de suporte e de gerenciamento, sendo todos considerados processos de negócio.

De acordo com Milan e Versetti (2012), o mapeamento dos processos também ganha importância por sua função de registro e documentação histórica da organização. Sendo o aprendizado construído com base em conhecimentos e experiências passadas dos indivíduos (conhecimento tácito), a organização não pode se arriscar a perder lições e experiências conseguidas ao longo de muitos anos em função de seus funcionários migrarem de um emprego para outro ou se aposentarem (ASSOCIATION..., 2013).

O CBOK® (ASSOCIATION.., 2013) apresenta uma série de ferramentas, por ele denominada de notações para o mapeamento de processos, sendo a mais utilizada atualmente a Business Process Management Notation (BPMN). Um importante compilado de ferramentas mais focadas em serviços é apresentado em Santos e Varvakis (2001) onde são ilustradas diversas metodologias e fluxos de processo em serviços com uma análise dos seus pontos fortes e fracos. Mais recentemente, Kluska, Lima e Costa (2015) apresentam sistemas de informações para gestão de processos de negócio com base em estudo realizado pela Gartner Group.

Os resultados da gestão por processos, impulsionados pelo padrão CBOK®, têm ampla divulgação no meio empresarial, sem, entretanto, serem tão extensamente refletidos em referências de caráter científico. Pode-se, entretanto, apontar alguns estudos como o de Gonçalves (2000b) onde são questionados os resultados de implantação de sistemas de informação quando os projetos de automação enfocam processos de suporte ou gerenciais, e não processos primários propriamente ditos implicando nos parcos resultados das iniciativas. 
Silva e Pereira (2006) estudaram o impacto da modelagem de processos quando da implantação de sistemas de informação em pequenas e médias empresas diagnosticando que a integração conseguida pelo uso dos sistemas é maior quando há um trabalho prévio de modelagem. Entretanto, observam que tal integração é mais evidente na indústria que em serviços, o que pode ser explicado pela dificuldade de "visualização" dos serviços, dado seu caráter intangível.

Müller, Diesel e Sellito (2010) estudam a análise de processos e oportunidades de melhorias em uma empresa de serviços de cobrança. $\mathrm{O}$ artigo demonstra um trabalho de melhoria de processos em que foram reduzidos $40 \%$ dos custos no processo de notificação, um aumento de $12 \%$ para $81 \%$ de pedidos de cobrança atendidos no prazo e uma média de cobranças realizadas em 40 dias ante os 61 dias anteriores.

Mückenberger et al. (2011) estudam a realização de convênios internacionais bilaterais em uma instituição de ensino superior pública brasileira utilizando a notação BPMN. Foi realizada a análise do processo com base em conceitos do CBOK(®) e identificadas as melhorias passíveis de serem aplicadas. Os autores enfocam como contribuição do estudo a simplificação e melhoria do processo de realização de convênios e a evidência de que o BPM é efetivo como instrumento de gestão e melhoria de processos.

Albuquerque (2012) relata uma experiência de implantação de gestão por processos em uma empresa de manutenção de aeronaves conseguindo melhorar a repetibilidade e confiabilidade dos processos de manutenção. Por outro lado, o autor descreve como os processos modelados implicaram em falta de flexibilidade para atender a mudanças eventuais mesmo com procedimentos de mudança formalizados. Milan e Versetti (2012) apresentam uma proposta de melhoria de processos em um laboratório de análises clínicas. O estudo é ilustrativo em demonstrar limitações do BPMN para expor gargalos, retrabalhos e operações desnecessárias, elementos que precisaram ser explicados textualmente pelos autores.

Alguns autores como Barbalho et al. (2016) apresentam métodos de melhoria de processos baseados na comparação de alguma técnica bem consolidada na literatura com casos reais de aplicação no Brasil, outros estudos propõem a 
integração de seis sigma com lean production como forma de prover melhorias a processos (PINHEIRO, SCHELLER e MIGUEL, 2013). No presente trabalho, utilizase uma abordagem que integra BPM e a mentalidade enxuta como forma de prover melhorias a processos administrativos, similarmente a Tegner et al. (2016). Assim, a seguir são apresentados conceitos de Lean.

\subsection{Mentalidade enxuta e processos administrativos}

Um dos principais métodos de melhoria de processos atualmente é baseado nos conceitos de produção enxuta. Segundo Endler et al. (2016) o Lean está entre as metodologias de melhoria de processos mais amplamente utilizadas nas empresas atualmente. Autores classificam a Mentalidade Enxuta (ME) como uma filosofia de gestão que visa melhorar as operações de uma dada empresa para oferecer o resultado esperado aos clientes (WOMACK e JONES, 2003). O enfoque da produção enxuta é a redução do custo pela redução do desperdício (OHNO, 1988), especialmente eliminando atividades desnecessárias não agregadoras de valor.

Embora tenha sido gerada em função de problemas vinculados à produção em massa (OHNO, 1988), nas últimas décadas há esforço de pesquisadores em adaptar os conceitos da produção enxuta ao âmbito dos serviços de maneira geral (LEITE e VIEIRA, 2015) e aos processos administrativos propriamente ditos, o que tem sido denominado Lean Office (GREEF, FREITAS e ROMANEL, 2012; TAPPING e SHUKER, 2010; DANIELSON, 2013). Estudiosos do Lean Office buscam caracterizar os desperdícios no âmbito dos escritórios (Quadro 1). 
Quadro 1 - Os sete desperdícios na manufatura e no escritório

\begin{tabular}{|c|c|c|}
\hline Item & Manufatura & Escritório \\
\hline $\begin{array}{l}\text { Processamento } \\
\text { sem valor }\end{array}$ & $\begin{array}{l}\text { Utilização errada de ferramentas, procedimentos } \\
\text { ou sistemas. }\end{array}$ & $\begin{array}{l}\text { Uso incorreto de procedimentos ou sistemas } \\
\text { inadequados, ao invés de abordagens simples e } \\
\text { eficazes. Excesso de assinaturas e revisões em } \\
\text { documentos ao longo de diferentes níveis na } \\
\text { organização. }\end{array}$ \\
\hline Superprodução & $\begin{array}{l}\text { Produzir excessivamente ou cedo demais, } \\
\text { resultado excesso de inventário. }\end{array}$ & $\begin{array}{l}\text { Gerar mais informações, em meio eletrônico ou } \\
\text { papéis, além do que se faz necessário, ou antes, } \\
\text { do correto momento. }\end{array}$ \\
\hline Inventário & $\begin{array}{l}\text { Excesso de matéria-prima, de peças em } \\
\text { processamento e estoque final. }\end{array}$ & $\begin{array}{l}\text { Alto volume de informação armazenado (Buffer } \\
\text { sobrecarregado). Relatórios produzidos em } \\
\text { excesso que ficam arquivados nos computadores. }\end{array}$ \\
\hline Defeito & Problema de qualidade do produto ou serviço. & $\begin{array}{l}\text { Erros frequentes de documentação, dados } \\
\text { incorretos registrados. Problemas na qualidade } \\
\text { dos serviços ou baixa performance de entrega. }\end{array}$ \\
\hline Transporte & $\begin{array}{l}\text { Movimento excessivo de pessoas ou peças, } \\
\text { resultado em dispêndio desnecessário de capital, } \\
\text { tempo e energia. }\end{array}$ & $\begin{array}{l}\text { Utilização excessiva de sistemas computacionais } \\
\text { nas comunicações. Fluxo de comunicações } \\
\text { superior ao demandado. }\end{array}$ \\
\hline Movimentação & $\begin{array}{l}\text { Desorganização do ambiente de trabalho, } \\
\text { resultado em baixa performance dos aspectos } \\
\text { ergonômicos e perda frequente de itens. }\end{array}$ & $\begin{array}{l}\text { Movimentação excessiva de pessoas e } \\
\text { informações entre áreas fisicamente diferentes. }\end{array}$ \\
\hline Espera & $\begin{array}{l}\text { Longos períodos de ociosidade de pessoas e } \\
\text { peças, decorrentes, por exemplo, de máquina em } \\
\text { manutenção ou em preparação (set-up), } \\
\text { resultando em lead time longo. }\end{array}$ & $\begin{array}{l}\text { Períodos de inatividade das pessoas e informações } \\
\text { (aprovações por assinatura, aguardar fotocópias, } \\
\text { esperar no telefone). }\end{array}$ \\
\hline
\end{tabular}

Fonte: Adaptado de: Seraphim et al. (2010); (Tapping e Shuker, 2010); Salgado et al. (2009)

Segundo Womack e Jones (2003) a ME possui 5 princípios: Valor, Cadeia de valor, Fluxo de Valor, Puxar a Produção e Perfeição. Segundo Greef, Freitas e Romanel (2012, p. 63), o valor consiste em oferecer benefícios aos clientes que o solicitam, da forma mais ágil e qualificada possível. O gerenciamento de fluxo de valor é um processo de planejamento de melhorias que permitirão que a empresa se torne Lean (Tapping e Shuker, 2010). Hines e Taylor (2000) aponta que apenas 1\% das informações geradas em processos administrativos agrega valor.

O valor é, portanto, o oposto do desperdício e o mapeamento do fluxo de valor (value stream mapping - VSM) é uma ferramenta básica para verificar desperdícios que estejam ocorrendo no modo como a organização vem produzindo valor ao cliente (ROTTER e SHOOK, 2012). O mapeamento de processos na abordagem enxuta é executado utilizando-se o VSM.

Godinho Filho e Fernandes (2004) compilam dados de 82 artigos sobre ME. Apenas um dos estudos enfocava na época a aplicação dos princípios enxutos em empresas de serviço. Os princípios enxutos mais abordados eram: produção 
puxada/just in time (JIT), trabalho/simplificação do fluxo e desenvolvimento e capacitação de recursos humanos. Os menos estudados eram gerenciamento visual e ordem, limpeza e segurança. O trabalho em equipe, o kanban e a tecnologia de grupo eram capacitadores de ME mais presentes na literatura, enquanto a utilização de medidas de performance enxutas e de gráficos de controle visuais eram os menos abordados.

Chay et al. (2015) aponta que a taxa de sucesso da implantação da mentalidade enxuta é baixa e que tal situação se deve à limitada participação dos funcionários de linha e seus supervisores. Os autores analisaram 15 modelos de implementação de Lean e identificaram um perfil muito baseado nas técnicas da produção enxuta e com pouca ênfase no aspecto humano, algo que sugerem poder explicar o baixo grau de sucesso da ME. Saurin et al. (2010) encontram situação similar em empresas brasileiras e indicam que há grande dificuldade em adaptar os conceitos enxutos à realidade das empresas pelo fato de as implantações serem baseadas em serviços de empresas de consultoria e haver pouco investimento em treinamento. A pesquisa dos autores aponta a produção puxada e a padronização do trabalho como os principais enfoques de aplicação de Lean nas empresas. Walter e Tubino (2013) realizaram análise de 48 estudos sobre implantação de ME, identificando que o maior enfoque é na aplicação das técnicas de produção puxada, troca rápida de ferramentas e integração de fornecedores.

Danielson (2013) classifica a implantação de Lean no Ocidente como neotaylorista em contraponto à abordagem "baseada em time" realizada nos países escandinavos. Para o autor, a abordagem neo-taylorista apresenta dificuldades em atingir o trabalho colaborativo por dois motivos: alta ênfase em padronização e não incorporação da rotação do líder do time.

Leite e Vieira (2015) apontam que as ferramentas mais usadas de produção enxuta na indústria de serviços são o mapeamento do fluxo de valor (VSM), o balanceamento da produção (heijunka), JIT e a padronização baseada no 5 S. Sellitto et al. (2010) estudam a presença dos princípios da mentalidade enxuta em empresas de serviços de transporte público em Porto Alegre. Os autores observam um enfoque de gestão reativo, uma vez que os custos da operação são 
compensados por contratos públicos, não havendo histórico de programas de melhorias ou redução de desperdícios.

Abdi et al. (2006) demonstram aplicações de técnicas de mapeamento e melhoria de processos em serviços baseadas nas ferramentas de ME. Piercy e Rich (2009) analisam a aplicação de ME no call center de três empresas do setor financeiro londrino. Após uma etapa de diagnóstico, na qual foram detectadas disfunções no modelo de gestão introduzido, os autores alteraram as medidas de desempenho e implantaram técnicas de gestão de recursos humanos mais adequadas às práticas enxutas. Os resultados foram reduções de $73 \%$, 44\% e 36\% nos lead times de atendimento dos clientes nos call centers e resultados positivos na moral do time, absenteísmo e turnover.

Barbalho et al. (2008) estudam a melhoria do processo de aquisição de materiais e componentes importados para protótipos de novos produtos em uma empresa de desenvolvimento de equipamentos de alta tecnologia. O processo de importação foi inicialmente mapeado em VSM para identificar os principais desperdícios que eram relativos às trocas de informações entre os setores envolvidos. Uma proposta de melhoria foi implementada tendo reduzido o lead-time dos itens importados em $57,6 \%$, e as filas em $76,9 \%$.

Salgado et al. (2009) consolida dados de desperdício do processo de desenvolvimento de produtos em empresa de autopeças com base na utilização de VSM. Os autores elaboraram proposta que reduziria em $54,8 \%$ os lead times aumentando em $24,4 \%$ e $67,2 \%$ o valor agregado e a eficiência, respectivamente.

Alguns países estão avançados na implementação do Lean no serviço público. Danielsson (2013) reporta que no ano de 2007 projetos de produção enxuta haviam sido implementados em $70 \%$ das municipalidades e $50 \%$ das operações do Governo central na Dinamarca. O Lean no serviço público é abordado em Seraphim et al. (2010), que relata esforço de implantação de ME em uma organização militar. Os autores reportam que a agregação de valor saltou de 1,7\% para 8,2\% e o leadtime passou de 18 dias para 4 dias, melhoria permitida por meio de padronização, reforço à motivação da equipe e redução de atividades não-agregadoras de valor.

Tegner et al. (2016) propõem um método para a implantação do Lean em áreas administrativas, incorporando técnicas de Gerenciamento de Processos de 
Negócio. O método abrange elementos não tratados no texto seminal de Tapping e Shuker (2010) como a mobilização de recursos, treinamento da equipe de melhoria, detalhamento dos modelos de processo AS-IS e TO-BE utilizando a modelagem Event-Process Chain (EPC) da metodologia ARIS (Architecture of Integrated Information System) e variações da ferramenta SIPOC, e utilização da ferramenta 5W1H para elaboração de planos de ação para implementar o processo TO-BE. O método foi aplicado e os autores relatam resultados positivos, apesar de não apresentarem indicadores de melhoria.

A integração entre a mentalidade enxuta e a metodologia de melhoria baseada em seis sigma tem sido discutida nos últimos anos (ENDLER et al., 2016), analisada (PINHEIRO, SCHELLER e MIGUEL, 2013) e implementada em estudos de caso (SCHELLER e MIGUEL, 2014), sendo importante tópico para delinear futuros trabalhos em melhoria de processos.

\section{PROCEDIMENTOS METODOLÓGICOS}

\subsection{Objetivos de Estudo}

O objeto deste estudo é o processo de trabalho necessário ao programa de intercâmbio PEE-AUGM de uma Instituição Federal de Ensino Superior, aqui denominada de Universidade Federal, que utiliza a mobilidade acadêmica como um pilar de sua internacionalização.

A Universidade Federal foi fundada em 1968, iniciou suas atividades em 1970 e possui 4 (quatro) campi. A Secretaria Geral de Relações Internacionais, SRInter, é um órgão de apoio à Reitoria cuja missão é propor e desenvolver a política de relações internacionais para intensificar a atuação da Universidade em programas de mobilidade e induzir/consolidar a internacionalização.

A SRInter conta com a seguinte estrutura organizacional: Secretaria Geral, Divisão de Convênios Internacionais, Divisão de Mobilidade e Secretaria Executiva. A Divisão de Mobilidade é responsável pelos diversos programas de mobilidade docente e discente na Instituição. Existem duas modalidades de intercâmbio: Incoming - do exterior para o Brasil e Outgoing - do Brasil para o exterior. 
Optou-se por enfocar os processos de outgoing por representarem maior volume de estudantes em mobilidade e por abrangerem maior conjunto de atividades realizadas por parte da Divisão de Mobilidade. Semestralmente é lançado um Edital para a participação de 11 alunos outgoing no referido Programa desde 2001, representando fluxo de trabalho com 33 alunos por vez - já que os intercâmbios duram um ano - e um histórico de 15 anos de atividades.

\subsection{Metodologia e coleta de dados}

Utilizou-se o seguinte procedimento para a melhoria de processos do PEEAUGM: (1) mapeamento dos processos pertencentes ao macroprocesso; (2) detalhamento das atividades desses processos utilizando fluxogramas de processo; (3) consolidação de mapa de fluxo de valor para a situação atual do macroprocesso e realização de análise crítica dos desperdícios ocorridos em cada processo; (4) listagem das sugestões de melhoria baseadas no ataque aos desperdícios identificados e (5) foi criado um VSM para o estado futuro. Essa sequência é apresentada na seção seguinte.

Os dados coletados para o mapeamento do processo tiveram na participação de um dos autores deste artigo como integrante da SRInter o seu fator determinante. Tal participação facilitou o acesso à documentação utilizada pela diretoria para realizar suas atividades, assim como ao formato e conteúdo dos documentos de formalização da participação dos alunos, às mensagens de e-mail trocadas pela diretoria com alunos e coordenadores de cursos de graduação, com as Universidades parceiras e com órgãos de administração da Universidade.

Assim, a sistematização dos fluxogramas de processo foi realizada inicialmente pelo autor participante do processo durando aproximadamente quatro meses. Tais fluxos foram analisados pelos demais membros da pesquisa ação em reuniões presenciais e refinados via análise textual durante cerca de três meses.

A elaboração do VSM e a análise dos desperdícios foi realizada em conjunto pelos pesquisadores uma vez que demandam maior aprofundamento dos dados, algo realizado mais efetivamente por um grupo que coadune diferentes visões sobre o processo. Uma vez que os VSM sintetizam um grande conjunto de informações em 
um diagrama enxuto e visual, observou-se que sua elaboração demandaria maior esforço dos pesquisadores com caráter sênior que os fluxogramas de processo. Assim, a sistematização do VSM e a análise dos desperdícios foi realizada paulatinamente, focando inicialmente na identificação de desperdícios nos próprios fluxogramas de processo, e posteriormente consolidando o VSM para análise final dos desperdícios de maneira agregada. Essa etapa foi realizada também via momentos presenciais e de análise textual e discussões com base nos fluxogramas propriamente ditos durando aproximadamente quatro meses.

Os pontos de melhoria foram incorporados ao processo pelo pesquisador participante ou discutidos por este junto à sua chefia e colegas de setor. Basicamente as melhorias que constam no presente texto foram implementadas na SRInter gerando o grau de melhoria apresentado na seção 5.

\section{PESQUISA-AÇÃO REALIZADA}

\subsection{Caracterização do processo}

A operacionalização dos programas de mobilidade compreende a elaboração do edital, orientações para a realização da mobilidade aos alunos e às coordenações de curso, aspectos relativos à vida acadêmica na Universidade pesquisada e na Universidade de destino, acompanhamento do aluno no exterior, orientações quanto aos procedimentos a realizar no retorno e acompanhamento do reconhecimento/lançamento dos créditos cursados pelo estudante no exterior.

Para ocorrer a mobilidade do PEE-AUGM procedimentos administrativos formalizados em edital são realizados para a seleção dos alunos, além do acompanhamento das coordenações de cursos cuja composição é, frequentemente, alterada pela dinâmica eletiva da Universidade.

O processo se inicia com a elaboração do Edital que demanda análise de histórico das chamadas para escolher os cursos elegíveis. Adicionalmente, para alunos selecionados cujos cursos não pertencem ao campus sede, há dificuldade adicional para acompanhamento das providências a serem tomadas. Há documentos que devem ser preenchidos corretamente para validação das etapas: 
plano de ensino, termo de compromisso, comprovação da chegada ao destino e documentação de reconhecimento das disciplinas cursadas.

Além disso, a instituição estudada segue os princípios burocráticos do serviço público, no qual cada atividade a realizar envolve a emissão de documentos que tramitam por vários departamentos até ser efetivamente executada. Para se efetuar um pagamento, exemplificando, são necessários vários documentos e trâmites, como elaborar um plano de aplicação com o montante a utilizar, solicitar autorização para debitar essa quantia do valor total do orçamento estipulado para o setor e requerer a abertura de empenho no valor solicitado. Após ser emitida a nota de empenho é que efetivamente pode haver o pagamento. E, neste caso, também é necessário enviar aos setores financeiros um documento com os dados bancários dos alunos.

\subsection{Mapeamento do processo}

As seguintes etapas foram realizadas para sistematizar o processo de alunos outgoing visando facilitar a discussão com os stakeholders - procedimentos um e dois da metodologia apresentada na seção anterior: (1) etapa 1 - elaboração do mapa do macroprocesso; (2) etapa 2 - elaboração de mapa de cada etapa do macroprocesso em nível agregado; (3) etapa 3 - elaboração de mapa detalhado com as atividades de cada etapa do macroprocesso; (4) etapa 4 - análise das informações geradas e utilizadas em cada subprocesso do macroprocesso, assim como suas saídas e utilização pelas etapas sucessoras e (5) etapa 5 - análise das ferramentas utilizadas para a gestão do processo sistematizado.

Essas etapas foram realizadas integralmente pelo pesquisador participante do mapeamento e melhoria. E, posteriormente, validadas junto à equipe externa e aos demais participantes da iniciativa. Os resultados desses procedimentos são apresentados a seguir com ilustrações de alguns dos processos mapeados.

As atividades do macroprocesso do PEE-AUGM são: definição de vagas no âmbito das Universidades parceiras; definição de vagas no âmbito da Universidade Federal com lançamento do Edital; recebimento pela SRInter dos nomes dos 3 (três) alunos selecionados pelas coordenações de curso com documentação requerida; 
formalização do aceite pelo aluno titular através do envio de informações para subsidiar o aceite. Há, então, o envio do formulário E1E2 da AUGM aos alunos selecionados e cada um destes, junto ao coordenador de curso, define disciplinas para o plano de ensino. É recebido o plano de ensino pela SRInter para assinaturas institucionais e envio à Universidade de destino do aluno. Recebe-se a carta de aceite e providências são tomadas para pagamento das bolsas aos alunos. A seguir, monitora-se a chegada do aluno ao destino para regularização da vida acadêmica na Universidade Federal. À medida que o intercâmbio esteja próximo ao final são atualizadas informações sobre ementas das disciplinas e mudanças do plano de ensino (formulário E3) para facilitar o reconhecimento das disciplinas. Ao retornar o aluno deve requerer 0 reconhecimento de disciplinas mediante envio da documentação ao coordenador de curso para análise e emissão de parecer relativo ao mesmo.

A Figura 1 apresenta os processos relativos ao macroprocesso do PEEAUGM para alunos outgoing conforme descrito.

Figura 1 - Processos utilizados no Macroprocesso do PEE-AUGM outgoing

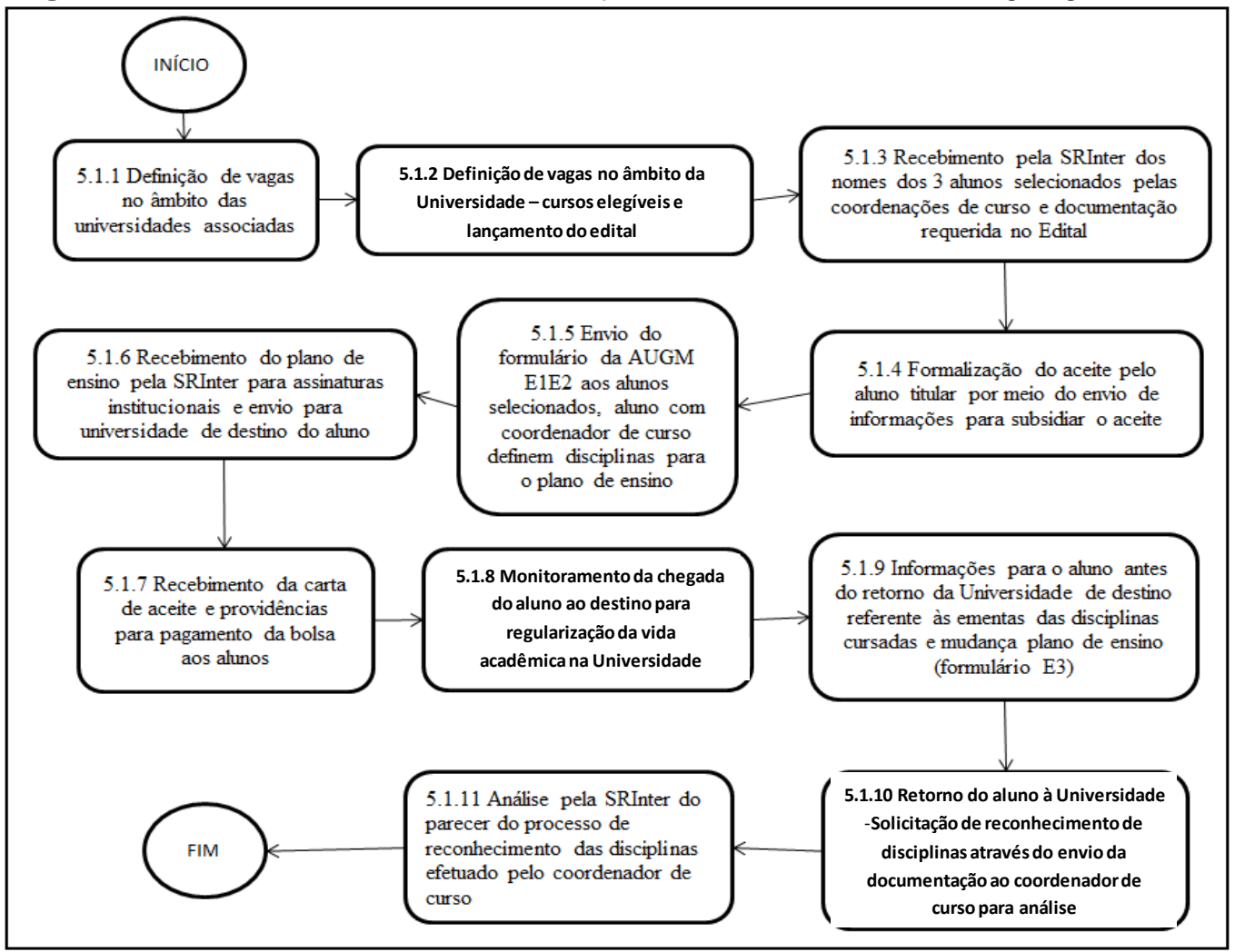

Fonte: Autores

Revista Produção Online. Florianópolis, SC, v.17, n. 2, p. 406-439, 2017. 
Após identificar a visão geral dos processos pertencentes ao PEE-AUGM (Figura 1), passou-se à etapa 2 que é exemplificada pelo subprocesso 5.1.4. Detalha-se este processo demonstrando sua interface com os demais, conforme Figura 2.

Figura 2 - Processo de formalização do aceite pelo aluno titular

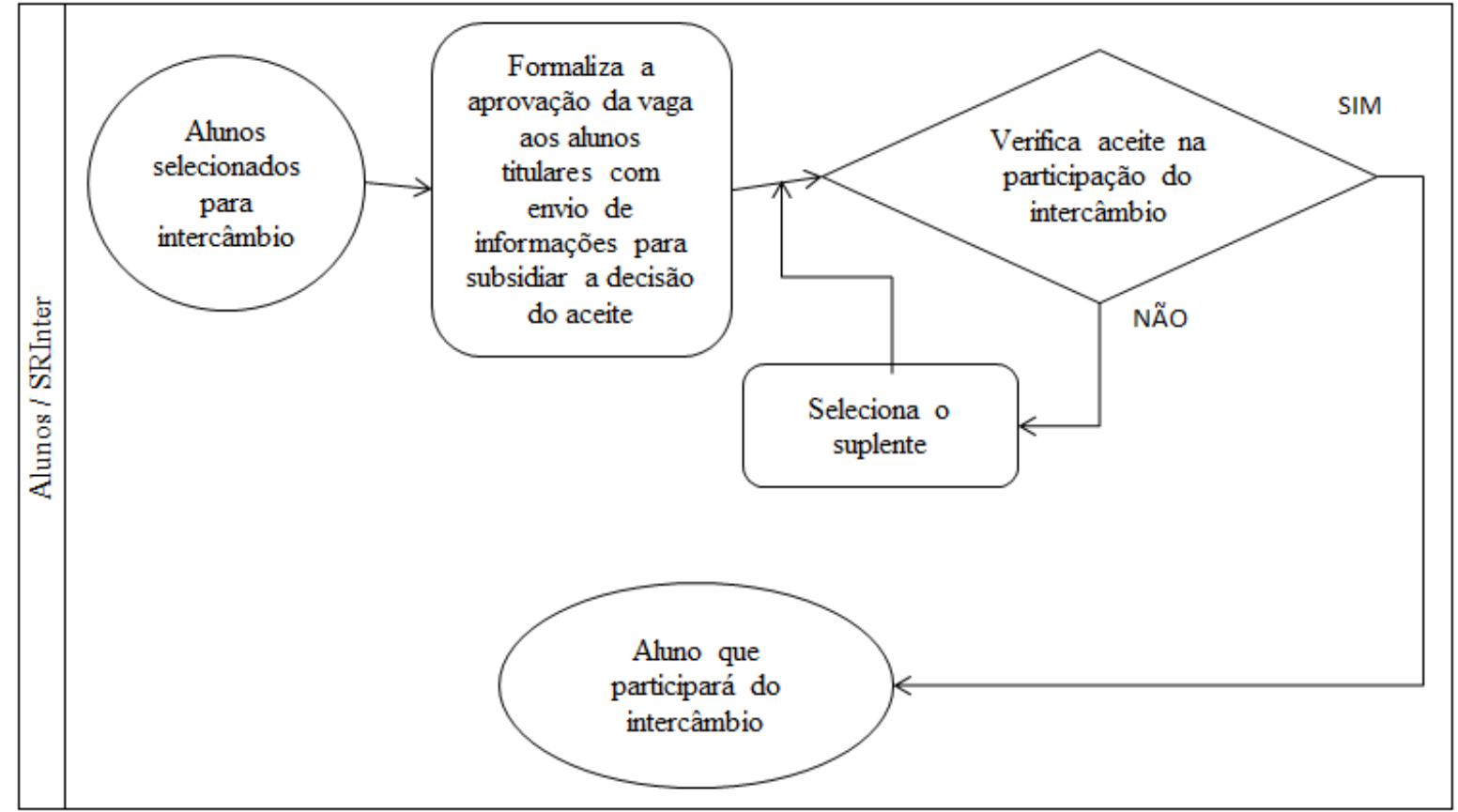

Fonte: Autores

Desse modo, a formalização do aceite tem como fornecedor os alunos titulares aprovados. Tem como entrada os nomes dos alunos titulares selecionados pelos coordenadores dos cursos elegíveis e validados, após análise pela SRInter. O processo consiste em os alunos formalizarem o aceite para participar ou não do intercâmbio. Para subsidiar a sua decisão são enviadas informações de suporte, como contatos de alunos que participam ou participaram do intercâmbio na universidade de destino. É enviado também um formulário para ser preenchido com os dados bancários. Na eventual desistência do aluno titular selecionado, a SRInter irá consultar o aluno indicado como suplente. A saída do processo é a informação recebida pela SRInter com a decisão dos alunos pertencentes aos cursos elegíveis no Edital de que efetivamente participarão do intercâmbio.

Passa-se à etapa $3 \mathrm{em}$ que as atividades de cada subprocesso são detalhadas sendo pré-indicados pontos de melhorias a serem revisados quando da 
construção do VSM. No caso do processo ilustrado (processo 5.1.4), tem-se que ele consiste em enviar um e-mail aos alunos titulares selecionados para a decisão do aceite final para a participação no intercâmbio. A mensagem consiste em informações úteis para que o aluno decida se quer participar efetivamente do programa. Em anexo à mensagem é enviado o Formulário de Dados Pessoais, que será preenchido após o aceite do aluno. Nele constam, além dos dados pessoais, os dados bancários do aluno para o pagamento da bolsa, antes de sua partida, conforme Figura 3.

Para subsidiar a identificação de possíveis melhorias ao processo, é importante analisar o processo seguinte, para o qual o analisado gera inputs, o que é realizado na etapa 4. No caso, para o processo 5.1.4, a seguir, há o recebimento pela SRInter da resposta do aluno com o aceite ou não da participação no intercâmbio. Se o aluno titular não aceitou é enviada mensagem ao $1^{\circ}$ suplente. Se não há o $1^{\circ}$ suplente, a SRInter analisa a possibilidade de abrir novo Edital considerando o cronograma do programa, o que pode tornar inviável cronologicamente a efetivação do intercâmbio para o curso relacionado ao aluno desistente. Ou seja, é importante para a SRInter que o aluno selecionado pela coordenação do curso aceite, daí o empenho dos responsáveis pelo processo em motivar o aluno a participar do programa.

Quando o aluno aceita participar do programa, é comum que haja uma grande quantidade de dúvidas do aluno e de familiares via e-mail, telefonema e presencialmente para entender detalhes do intercâmbio. Como o fluxo é contínuo e, portanto, no ano corrente os alunos do ano anterior estão em processo de retorno e formalização do aproveitamento de disciplinas e assim por diante, o trabalho operacional é volumoso. Ainda quanto ao fluxo da figura 3, quando sanadas todas as dúvidas e definidos os alunos, a SRInter elabora uma planilha em MS-Excel denominada follow up, com a indicação do ano e semestre letivo do intercâmbio. Nessa planilha estão consolidadas todas as informações relativas ao intercâmbio de todos os alunos em viagem, selecionados e já retornados, especialmente as datas limites de cada ação necessária ao intercâmbio. A planilha auxilia a SRInter para verificar se os prazos estão sendo cumpridos. Caso o aluno esteja atrasado com o cronograma é enviada mensagem para que ele cumpra as ações solicitadas. 
Figura 3 - Processos utilizados no Macroprocesso de PEE-AUGM outgoing (ASIS)

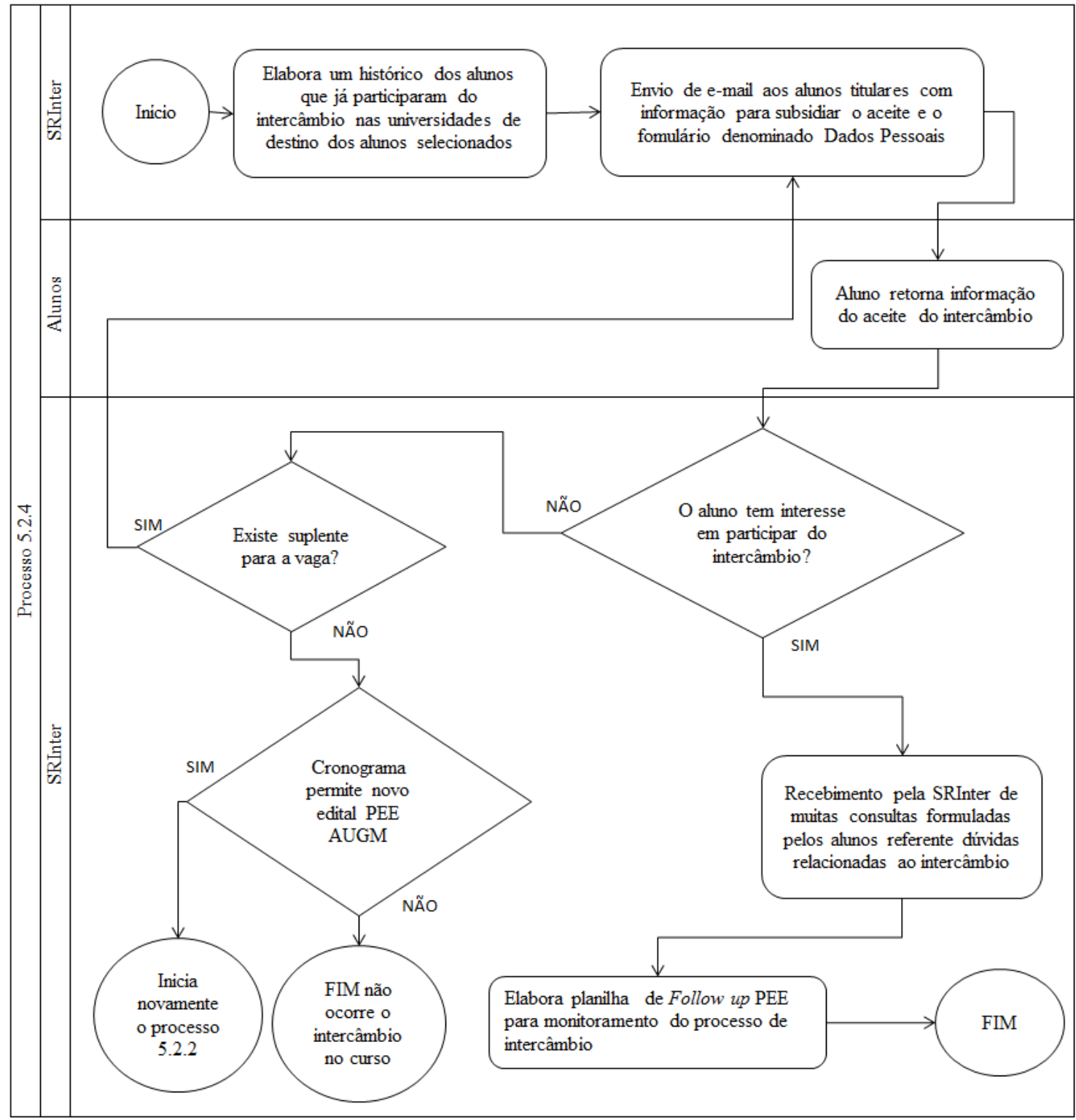

Fonte: Autores

O descritivo aqui apresentado foi elaborado para todos os processos apresentados na Figura 1 indicando detalhadamente todas as atividades, formulários e ferramentas de gestão utilizadas para alunos outgoing.

\subsection{VSM do Estado Atual}

Sistematizados todos os processos de outgoing foi desenvolvido um VSM do estado atual (Figura 4). O desenvolvimento do VSM ocorreu paralelo à 
sistematização dos desperdícios do processo. Algumas correções nos fluxogramas de processo foram realizadas em função do VSM e dos desperdícios identificados. Adicionalmente, foi elaborado um SIPOC (Supplier, Input, Process, Output, Customer - ASSOCIATION..., 2013) com uma visão geral do macroprocesso. Nessa ferramenta, as saídas principais e os atores envolvidos no processo são identificados de uma maneira sumarizada. Por considerar-se que o SIPOC apresenta informação similar ao VSM, sem, entretanto, ilustrar os desperdícios de maneira mais sistemática, optou-se por não apresentá-lo no artigo, apesar de ele ter sido importante para delimitar os pontos de melhoria, e especialmente para comunicá-los às partes interessadas de uma maneira mais fácil de ser compreendida que o VSM.

O VSM atual enfocou as atividades e informações do processo, não incluindo métricas como fila, lead time ou tempo de espera, visto que seriam estimativas muito grosseiras já que não havia gestão de tempos com grau de detalhe necessário para computar tais informações. Adicionalmente, considerou-se que a identificação de desperdícios permitida pelos mapas elaborados e complementada pelo VSM já possibilitaria a identificação de melhorias significativas.

A partir da elaboração do VSM atual e da identificação de desperdícios, passou-se à análise das oportunidades de melhoria de maneira global, e por fim, à elaboração de processos TO-BE e do VSM do estado futuro. Tais elementos são apresentados nas seções seguintes.

\subsection{Desperdícios e pontos de melhoria}

Os desperdícios e pontos de melhoria do processo analisado, com base nos conceitos do Lean Office são apresentados no Quadro 2. 
Figura 4 - Fluxo de valor atual para o PEE AUGM

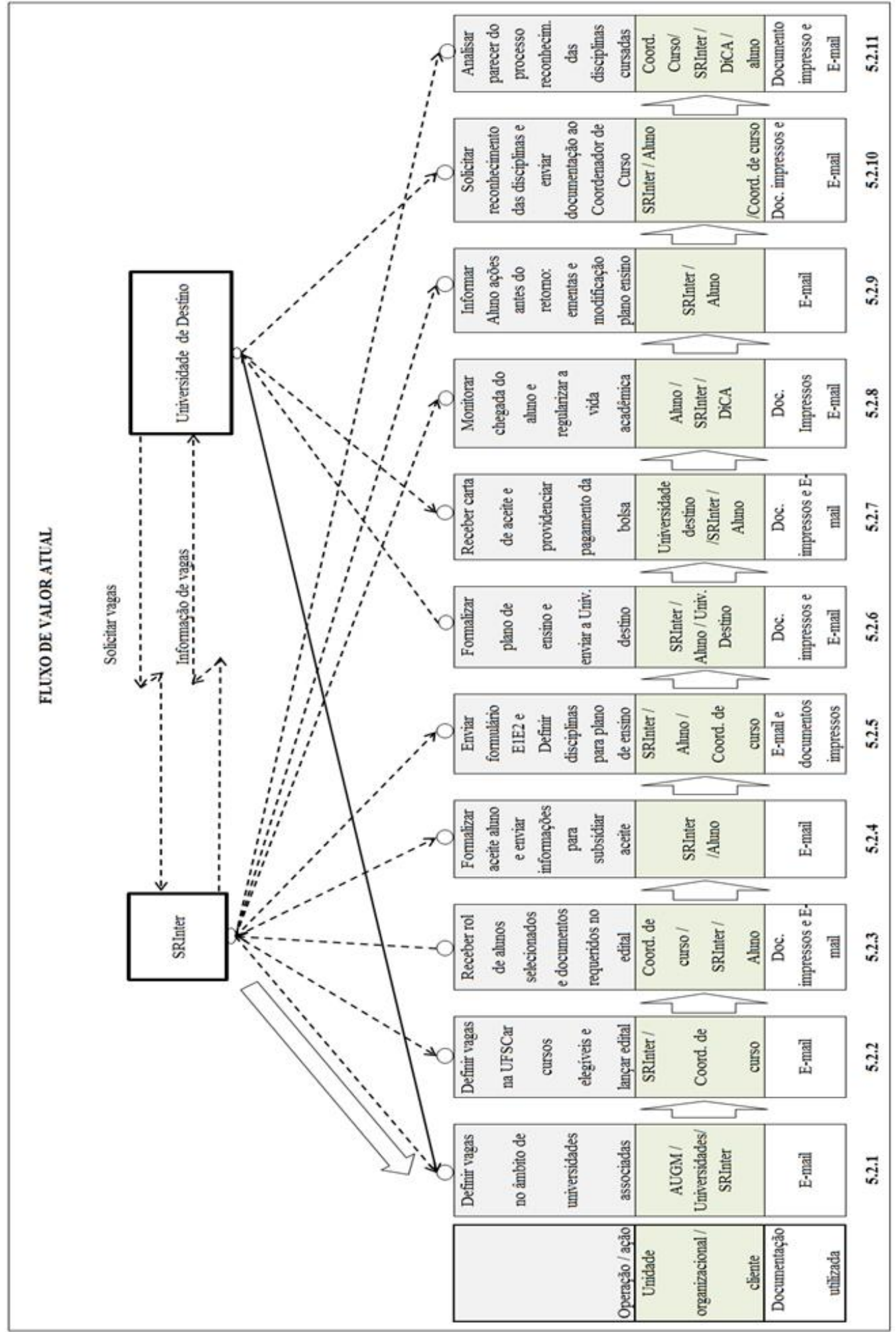

Fonte: Autores

Revista Produção Online. Florianópolis, SC, v.17, n. 2, p. 406-439, 2017. 


\begin{tabular}{|c|c|c|}
\hline Processo & Desperdícios & Melhorias propostas \\
\hline $\begin{array}{l}\text { 5.1.1 Definição de vagas } \\
\text { no âmbito das } \\
\text { Universidades associadas }\end{array}$ & $\begin{array}{l}\text { defeito: erros frequentes de } \\
\text { documentação. } \\
\text { superprodução: gerar mais } \\
\text { informações em meio eletrônico } \\
\text { ou papéis, além do que se faz } \\
\text { necessário. } \\
\text { transporte: utilização excessiva } \\
\text { de sistemas computacionais nas } \\
\text { comunicações. } \\
\text { processamento sem valor: uso } \\
\text { incorreto de procedimentos ou } \\
\text { sistemas inadequados, ao invés } \\
\text { de abordagens simples e } \\
\text { eficazes. }\end{array}$ & $\begin{array}{l}\text { o estado ideal é que não haja, após a reunião, o envio do quadro de vagas para conferência } \\
\text { do que foi acordado. Se há a leitura da negociação na própria reunião e todos concordam, } \\
\text { não devem ocorrer erros da decisão realizada. A secretaria executiva pode elaborar, após a } \\
\text { discussão das vagas entre as Universidades membros, uma tabela com as definições de } \\
\text { vagas e expor por data show no momento da reunião para conferência e pronunciamento, } \\
\text { caso haja conflito. Só haveria o envio de uma única mensagem com o lançamento oficial } \\
\text { da mobilidade. Embora essa ação não pertença à SRInter, mesmo assim é apontada a } \\
\text { melhoria } \\
\text { Resumo melhoria: com o uso de ferramenta adequada implica na diminuição de } \\
\text { informações eletrônicas. }\end{array}$ \\
\hline $\begin{array}{l}\text { 5.1.2 Definição de vagas } \\
\text { no âmbito da UFSCar } \\
\text { cursos elegíveis e } \\
\text { lançamento do Edital }\end{array}$ & \begin{tabular}{|l|} 
defeito: erros frequentes de \\
documentação. \\
superprodução: gerar mais \\
informações em meio eletrônico \\
ou papéis, além do que se faz \\
necessário. \\
processamento sem valor: uso \\
incorreto de procedimentos ou \\
sistemas inadequados ao invés \\
de abordagens simples e \\
eficazes
\end{tabular} & $\begin{array}{l}\text { 1. não deve ocorrer a checagem junto à coordenação de curso a respeito do recebimento } \\
\text { do e-mail referente ao Edital. Se a mensagem é enviada com aviso de recebimento, a } \\
\text { simples execução do aviso, por si só, já bastaria, não sendo necessária a perda de tempo } \\
\text { com uma ligação para comprovação. Neste caso tem-se menos desperdício com a } \\
\text { diminuição de ligações telefônicas e mensagens eletrônicas. } \\
\text { 2. o envio de informações ao coordenador de curso juntamente com o Edital com } \\
\text { procedimentos a serem observados para realizar a seleção dos alunos pode ocasionar a } \\
\text { redução de ligações e e-mails com dúvidas, principalmente para os coordenadores de curso } \\
\text { que assumiram a função recentemente e não têm experiência em atividades } \\
\text { administrativas. } \\
\text { Resumo melhorias: envio do procedimentos implica na diminuição do desperdício } \\
\text { informações (e-mails e ligações) e consequentemente abordagem mais eficaz. }\end{array}$ \\
\hline $\begin{array}{l}\text { 5.1.3 Recebimento pela } \\
\text { SRInter dos nomes dos } 3 \\
\text { alunos selecionados pelas } \\
\text { coordenações de curso e } \\
\text { documentação requerida } \\
\text { no Edital }\end{array}$ & \begin{tabular}{|l|} 
defeito: erros frequentes de \\
documentação. \\
superprodução: gerar mais \\
informações em meio eletrônico \\
ou papéis, além do que se faz \\
necessário. \\
espera: períodos de inatividade \\
das pessoas e informações.
\end{tabular} & $\begin{array}{l}\text { 1. conferir a documentação recebida para verificar se foram cumpridas as exigências do } \\
\text { Edital, assim como a falta de classificação dos alunos gera um retrabalho. O Edital é } \\
\text { explícito, o coordenador deve selecionar os } 3 \text { alunos seguindo uma classificação, portanto } \\
\text { o resultado da seleção não deve gerar dúvidas. } \\
\text { 2. não receber informaçães sobre o processo seletivo também gera retrabalho. Um simples } \\
\text { e-mail da coordenação de curso dizendo que não houve inscritos seria suficiente. } \\
\text { 3. a elaboração de um novo Edital, caso não haja inscritos, ocasiona a necessidade de se } \\
\text { realizar todos os procedimentos constantes na atividade 5.2.2. Uma melhoria importante é } \\
\text { inserir quando da elaboração do Edital a informação de que a SRInter tem autonomia do } \\
\text { remanejamento da vaga não ocupada para outro curso elegível utilizando a seleção } \\
\text { realizada, tendo como base o histórico de editais anteriores. Portanto, no novo mapa não } \\
\text { haverá o retorno para as atividades } 5.2 .2 \\
\text { Resumo Melhorias: inclusão de informação vaga remanescente no Edital implica na } \\
\text { exclusão de atividade no processo e agregação de valor. Cumprir com as regras do Edital e } \\
\text { cronograma elimina retrabalho e diminuição de informações em meio eletrônico }\end{array}$ \\
\hline
\end{tabular}

Revista Produção Online. Florianópolis, SC, v.17, n. 2, p. 406-439, 2017. 


\begin{tabular}{|c|c|c|}
\hline Processo & Desperdícios & Melhorias propostas \\
\hline $\begin{array}{l}\text { 5.1.4 Formalização do } \\
\text { aceite pelo aluno titular } \\
\text { por meio do envio de } \\
\text { informações para } \\
\text { subsidiar o aceite }\end{array}$ & \begin{tabular}{|l} 
defeito: erros frequentes de \\
documentação. \\
superprodução: gerar mais \\
informações em meio eletrônico \\
ou papéis, além do que se faz \\
necessário. \\
espera: períodos de inatividade \\
das pessoas e informações
\end{tabular} & $\begin{array}{l}\text { 1. considerando a quantidade de mensagens recebidas dos alunos com dúvidas em relação } \\
\text { ao intercâmbio e também à escolha das disciplinas a sugestão é fazer um documento mais } \\
\text { detalhado a respeito do intercâmbio e outro das disciplinas, informar endereço do Skype } \\
\text { para uma conversa pronta e rápida (em especial aos alunos dos outros campi). Esses } \\
\text { documentos enviados aos alunos reduzem as mensagens de dúvidas. } \\
\text { 2. o aluno que desiste irá gerar uma nova consulta ao suplente, se houver. Ele deve ter clara } \\
\text { a intenção de participar. } \\
\text { 3. a elaboração de um novo Edital, se não há inscritos ou desistentes sem suplentes ocasiona } \\
\text { a necessidade de se realizar todos os procedimentos constantes na atividade 5.2.2. Uma } \\
\text { melhoria importante é inserir quando da elaboração do Edital a informação de que a } \\
\text { SRInter tem autonomia do remanejamento da vaga não ocupada para outro curso elegível } \\
\text { utilizando a seleção realizada, tendo como base o histórico de editais anteriores. Portanto, } \\
\text { no novo mapa não haverá o retorno para as atividades 5.2.2. } \\
\text { Resumo melhorias: inclusão de informação vaga remanescente no Edital implica na } \\
\text { exclusão de atividade no processo e agregação de valor. Envio procedimentos implica } \\
\text { desperdício informações (e-mails e ligações) e consequentemente abordagem mais eficaz }\end{array}$ \\
\hline $\begin{array}{l}\text { 5.1.6 Recebimento do } \\
\text { plano de ensino pela } \\
\text { SRInter para assinaturas } \\
\text { institucionais e envio para } \\
\text { a Universidade de destino } \\
\text { do aluno }\end{array}$ & $\begin{array}{l}\text { defeito: erros frequentes de } \\
\text { documentação. } \\
\text { superprodução: gerar mais } \\
\text { informações em meio eletrônico } \\
\text { ou papéis, além do que se faz } \\
\text { necessário. } \\
\text { espera: períodos de inatividade } \\
\text { das pessoas e informações. }\end{array}$ & $\begin{array}{l}\text { 1. o aluno deve ter conhecimento dos prazos para a en trega dos formulários, pois já recebeu } \\
\text { as deadlines do Programa. O estado ideal é não ter que solicitar providências dos alunos. } \\
\text { Resumo melhoria: o uso da ferramenta adequada - documento Termo de Compromisso em } \\
\text { nova versão - implica na diminuição do tempo de espera para o recebimento de } \\
\text { documentos, consequentemente abordagem mais eficaz. }\end{array}$ \\
\hline
\end{tabular}

Revista Produção Online. Florianópolis, SC, v.17, n. 2, p. 406-439, 2017. 


\begin{tabular}{|c|c|c|}
\hline Processo & Desperdícios & Melhorias propostas \\
\hline $\begin{array}{l}5.1 .8 \text { Monitoramento } \\
\text { de chegada do aluno ao } \\
\text { destino para } \\
\text { regularização da vida } \\
\text { acadêmica na UFSCar }\end{array}$ & $\begin{array}{l}\text { defeito: erros frequentes de } \\
\text { documentação. } \\
\text { espera: períodos de } \\
\text { inatividade das pessoas e } \\
\text { informações. }\end{array}$ & $\begin{array}{l}\text { 1. as Universidades de destino devem encaminhar os formulários solicitados pela } \\
\text { SRInter. } \\
\text { devem ficar atentos ao envio dos formulários que devem providenciar quando } \\
\text { chegarem à Universidade de destino. O aluno deve estar consciente das ações que } \\
\text { são de sua responsabilidade, conforme informações contidas no Termo de } \\
\text { Compromisso, que foi assinado antes do pagamento da bolsa e da partida para o } \\
\text { intercâmbio. } \\
\text { Resumo melhoria: as ações já desenvolvidas e o uso da ferramenta adequada - } \\
\text { documento Termo de Compromisso em nova versão -implicam na diminuição do } \\
\text { tempo de espera para o recebimento de documentos colaborando para uma } \\
\text { abordagem mais eficaz. }\end{array}$ \\
\hline $\begin{array}{l}\text { 5.1.9 Informações para } \\
\text { o aluno antes do } \\
\text { retorno da } \\
\text { Universidade de } \\
\text { destino referente às } \\
\text { ementas das disciplinas } \\
\text { cursadas e mudança no } \\
\text { plano de ensino }\end{array}$ & $\begin{array}{l}\text { superprodução: gerar mais } \\
\text { informações, em meio } \\
\text { eletrônico ou papéis, além do } \\
\text { que se faz necessário ou } \\
\text { antes do correto momento. } \\
\text { transporte: uso excessivo de } \\
\text { sistemas computacionais nas } \\
\text { comunicações. }\end{array}$ & $\begin{array}{l}\text { 1. não deveria haver a necessidade de relembrar os alunos desta ação, porque já } \\
\text { assinaram um termo de compromisso antes da partida. Esse processo não irá mais } \\
\text { existir, em virtude do aluno já ter recebido instruções. } \\
\text { Resumo melhoria: o uso de ferramenta adequada - documento Termo de } \\
\text { Compromisso em nova versão - implica eliminação de um processo e } \\
\text { conseqüentemente abordagem mais eficaz. }\end{array}$ \\
\hline $\begin{array}{l}\text { 5.1.10 Retorno do } \\
\text { aluno à UFSCar- } \\
\text { solicitação de } \\
\text { reconhecimento de } \\
\text { disciplinas através do } \\
\text { envio de documentação } \\
\text { ao coordenador de } \\
\text { curso para análise }\end{array}$ & $\begin{array}{l}\text { defeito: erros frequentes de } \\
\text { documentação. } \\
\text { superprodução: gerar mais } \\
\text { informações em meio } \\
\text { eletrônico ou papéis, além do } \\
\text { que se faz necessário. } \\
\text { espera: períodos de } \\
\text { inatividade das pessoas e } \\
\text { informações }\end{array}$ & $\begin{array}{l}\text { 1. as Universidades membros do grupo participantes do Programa têm } \\
\text { conhecimento das regras e deveriam providenciar o histórico escolar do aluno no } \\
\text { final do intercâmbio, como determina o cronograma do Programa. } \\
\text { 2. a SRInter, como proposta de melhoria, envia ao coordenador de curso ofício que } \\
\text { detalha os pontos relevantes para balizá-lo quanto à análise da documentação } \\
\text { referente às disciplinas cursadas para a emissão do parecer a respeito do } \\
\text { reconhecimentor. } \\
\text { uso de ferramenta adequada - documento Termo de Compromisso em nova versão } \\
\text { - implica diminuição de informações eletrônicas. O documento enviado com } \\
\text { procedimentos implica diminuição do desperdício informações (e-mails e ligações) } \\
\text { e consequentemente abordagem mais eficaz. }\end{array}$ \\
\hline $\begin{array}{l}\text { 5.1.11 Análise pela } \\
\text { SRInter do parecer do } \\
\text { processo de } \\
\text { reconhecimento das } \\
\text { disciplinas efetuado } \\
\text { pelo coordenador de } \\
\text { curso }\end{array}$ & $\begin{array}{l}\text { defeito: erros frequentes de } \\
\text { documentação. } \\
\text { superprodução: gerar mais } \\
\text { informações em meio } \\
\text { eletrônico ou papéis, além do } \\
\text { que se faz necessário. } \\
\text { espera: períodos de } \\
\text { inatividade das pessoas e } \\
\text { informações. }\end{array}$ & $\begin{array}{l}\text { 1. os coordenadores de curso têm responsabilidades inerentes à sua função. Cabe a } \\
\text { eles a análise da documentação do aluno antes do próximo período de matrículas, } \\
\text { pois o aluno precisa desta informação para saber se deve se matricular em } \\
\text { determinada disciplina. Neste contexto não deve existir um período longo para a } \\
\text { realização da análise e a necessidade do envio de mensagem para solicitar o } \\
\text { parecer. Assim como houve um acordo no plano de estudos de reconhecimento de } \\
\text { determinada disciplina, há de se cumprir o acordo. } \\
\text { Resumo melhoria: o uso de ferramenta adequada implica diminuição do tempo de } \\
\text { espera para o recebimento de documentos e consequentemente abordagem mais } \\
\text { eficaz. }\end{array}$ \\
\hline
\end{tabular}

Fonte: Autores

Quanto ao subprocesso 5.1.4, utilizado ao longo desta seção para ilustrar o procedimento de melhoria utilizado, os desperdícios identificados foram: (1) desperdício defeito - erros frequentes de documentação; (2) desperdício superprodução - gerar mais informações que necessário em meio eletrônico ou papel; (3) desperdício espera - períodos de inatividade das pessoas e informações. Considerando-se a quantidade de mensagens recebidas dos alunos com dúvidas relativas ao intercâmbio, a sugestão de melhoria seria fazer um documento Revista Produção Online. Florianópolis, SC, v.17, n. 2, p. 406-439, 2017. 
mais detalhado dos procedimentos e informar endereço do Skype para uma conversa pronta e rápida. Considerando ainda as mensagens dos alunos com dúvidas quanto à escolha das disciplinas, a sugestão seria encorpar o documento a enviar com informações que ajudassem nessa tarefa.

O aluno que desiste gera uma nova consulta ao suplente, se houver. $O$ aluno deve ter clara a intenção de participação, pois o Edital já menciona o país da mobilidade, valor de bolsa etc. $O$ aluno declara na ficha de inscrição ter conhecimento do regulamento do PEE. A elaboração de um novo Edital, caso haja desistentes sem suplentes, torna necessário realizar novamente todos os procedimentos da atividade 5.2.2. Uma melhoria importante foi inserir quando da elaboração do Edital a informação de que a SRInter teria autonomia no remanejamento da vaga não ocupada para outro curso elegível tendo como base o histórico de editais anteriores.

Esse tipo de análise e proposição foi realizada para todos os processos da Figura 1.

\subsection{Situação TO-BE e mapa do estado futuro}

De maneira geral, considerou-se que, para o estágio atual do serviço prestado pela SRInter, e em função da impossibilidade de desenvolvimento de um software específico para a gestão do seu processo de trabalho, as melhores alternativas para reduzir os desperdícios seriam a elaboração de documentos padrão e o suporte no seu uso por parte dos alunos e do coordenador de curso. Nesse sentido, a SRInter buscaria alinhar as informações do processo com os participantes e provê-los com documentos de referência mais completos que os até então utilizados. Outras melhorias pontuais foram sugeridas nas etapas iniciais do processo e na interface com as Universidades de destino, mas a racionalização das informações com alunos e coordenadores de curso foi o ponto chave a ser tratado.

Discutidos os desperdícios com os decisores foram elaborados novos mapas (TO-BE) para cada processo. Ilustrativamente, apresenta-se na Figura 5, o processo 5.1.4 TO-BE. Propõe-se que não haja o retorno para as atividades 5.2.2 reduzindo assim retrabalhos e espera desnecessária. A sugestão de melhoria relacionada ao 
envio das informações aos alunos a respeito dos procedimentos do PEE contribuiria para reduzir o fluxo de mensagens pela SRInter.

Figura 5 - Processos utilizados no Macroprocesso de PEE-AUGM outgoing (TO-BE)

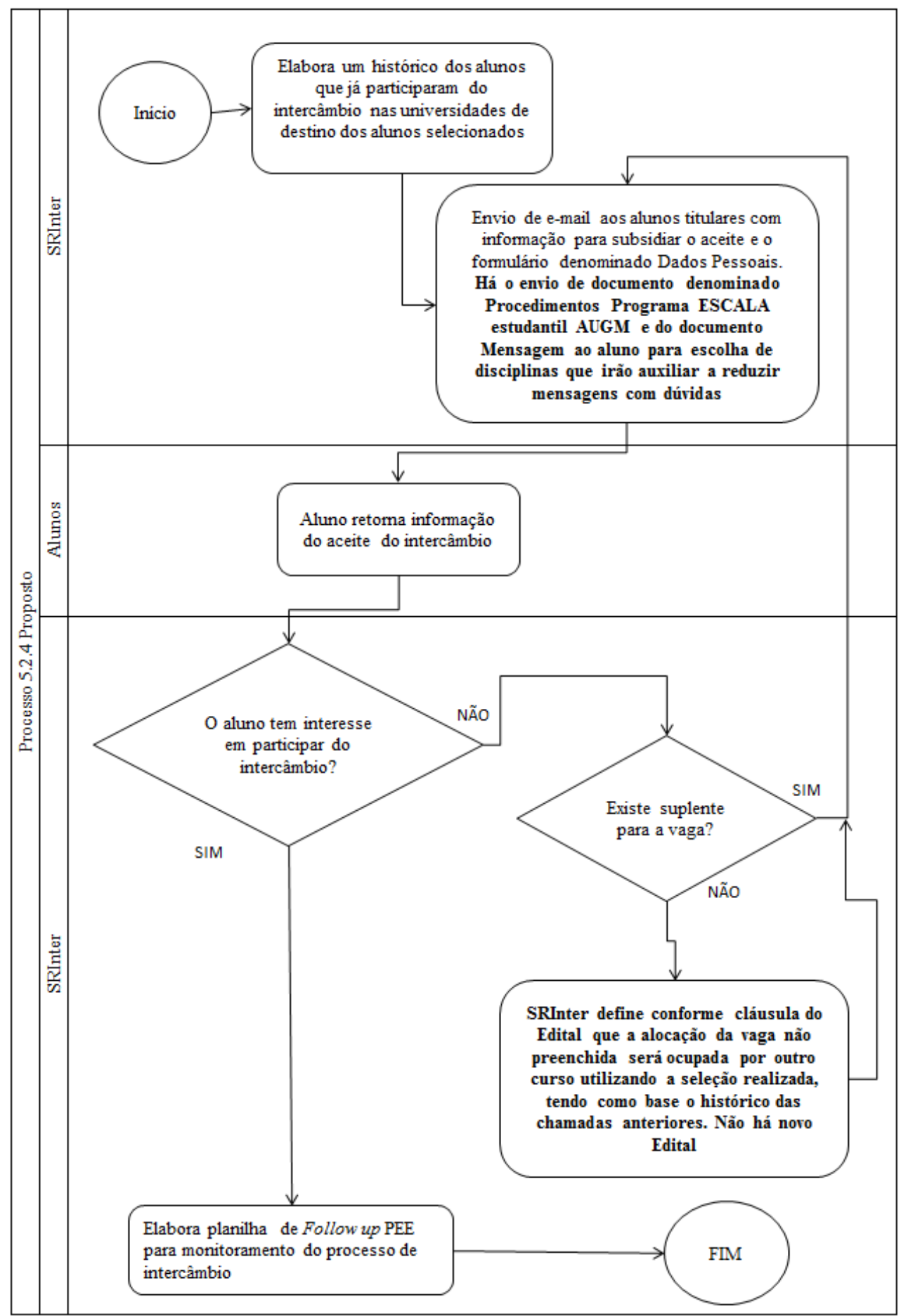

Fonte: Autores

Revista Produção Online. Florianópolis, SC, v.17, n. 2, p. 406-439, 2017. 
Depois de pensado o fluxograma futuro de cada processo foi elaborado um mapa do estado futuro resumindo a situação final do macroprocesso, a qual é apresentada na Figura 6.

Figura 6 - Fluxo de valor proposto para o PEE AUGM

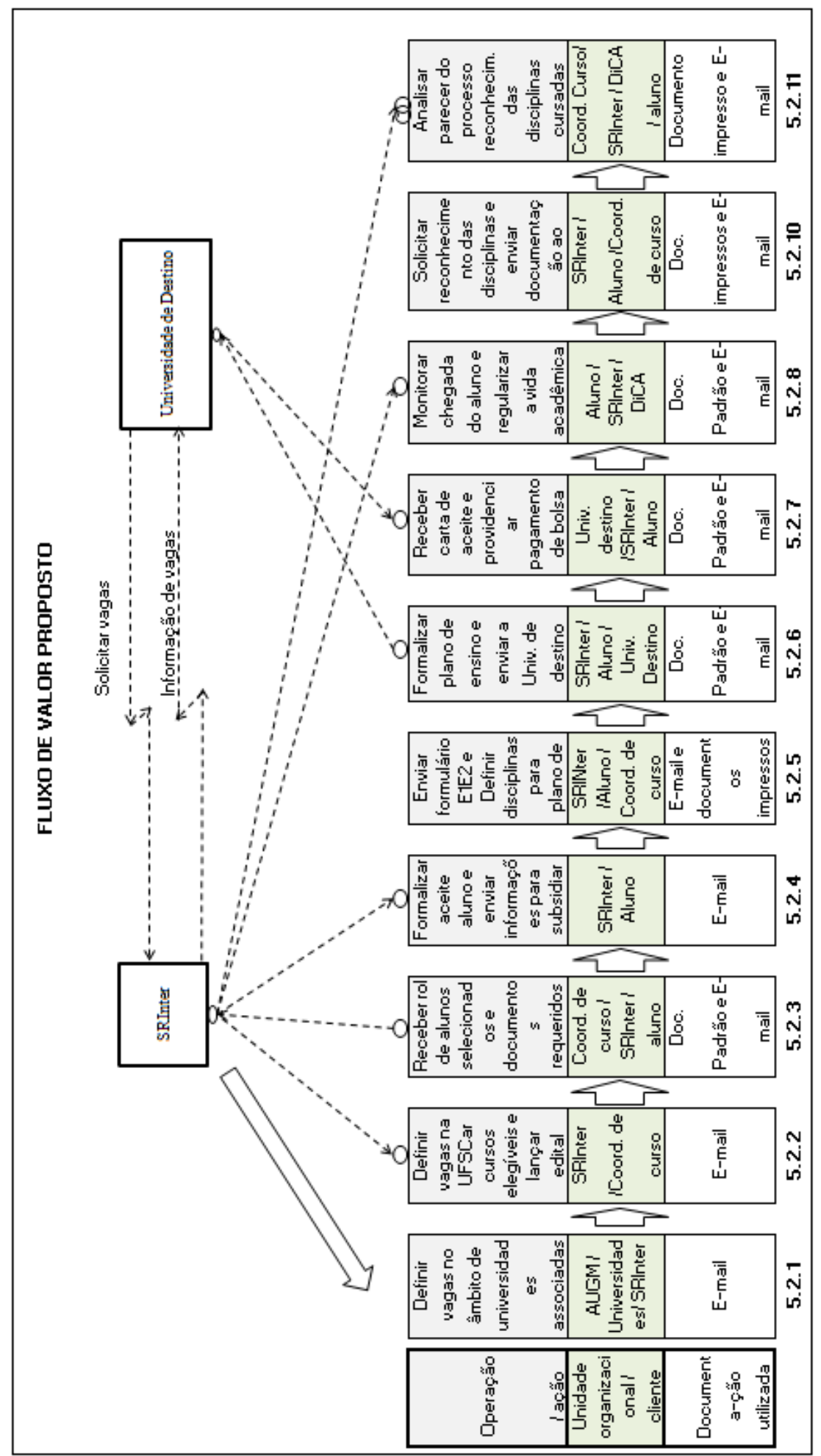

Fonte: Autores

Revista Produção Online. Florianópolis, SC, v.17, n. 2, p. 406-439, 2017. 
Analisando o fluxo de valor futuro em comparação com o fluxo de valor atual, alguns elementos ressaltam. Primeiramente, destaca-se a eliminação de um dos processos cuja função seria informar aos alunos que estão em intercâmbio a respeito de ações antes de seu retorno quanto às ementas das disciplinas e modificação no plano de ensino (ver processo 5.2.9 na Figura 1), pois o aluno já recebeu tais informações por meio do Termo de Compromisso, além de ser de seu interesse direto o aproveitamento das disciplinas cursadas no intercâmbio.

Outras iniciativas foram propostas no sentido de agregar valor e diminuir desperdícios. Neste caso, o Quadro 2 pode também auxiliar na comparação das figuras 4 e 6 . Considerando cada uma das diferenças-chave entre o mapa futuro e o atual, tem-se:

- O envio de informações ao coordenador de curso referente à seleção dos alunos reduz o recebimento pela SRInter de mensagens solicitando informações do "como fazer" (processo 5.2.1).

- A inclusão no Edital da indicação de que a SRInter terá autonomia para decidir sobre a vaga não preenchida em virtude de desistência ou de não inscritos elimina operações nos processos 5.2.3 e 5.2.4.

- O documento enviado ao aluno, com informações referentes à situação acadêmica relacionadas ao intercâmbio e procedimentos quanto à escolha de disciplinas, implica na diminuição do recebimento pela SRInter de mensagens com questionamentos (processos 5.2 .4 e 5.2.5).

- O aluno passa a ter conhecimento das datas limites e, portanto, a situação ideal para redução dos desperdícios que seria não ter tempo de espera no recebimento do plano de ensino preenchido e assinado pode contar com a coparticipação do aluno, o que atualmente é realizado inteiramente pelos responsáveis pela SRInter (processo 5.2.6).

- O Termo de Compromisso enviado para assinatura antes do pagamento da bolsa reduz mensagens dos alunos, pois contempla várias informações referentes à mobilidade, antes e depois da partida, auxiliando na redução dos desperdícios dos processos 5.2.7 e 5.2.8.

Revista Produção Online. Florianópolis, SC, v.17, n. 2, p. 406-439, 2017. 
- O envio de informações ao coordenador de curso referentes aos procedimentos de reconhecimento de disciplinas reduz o recebimento pela SRInter de mensagens solicitando informações do "como fazer", processo 5.2.10.

- A situação ideal para redução dos desperdícios no processo 5.2.11 é não haver tempo de espera no recebimento do parecer emitido pelo coordenador de curso referente à análise de reconhecimento das disciplinas cursadas, a qual se beneficia com o prévio envio das informações sobre o aproveitamento de disciplinas para o coordenador.

Analisando de maneira sistemática a melhoria proposta, observa-se que tais ações demandam um planejamento diferenciado da SRInter quanto à elaboração de documentos de referência mais completos e um trabalho de sensibilização dos alunos acerca dos procedimentos de trabalho necessários ao PEE-AUGM. São melhorias simples, mas ilustrativas de um grande universo de processos realizados pela Universidade pesquisada, conforme discussões da equipe de pesquisa com os principais stakeholders do processo.

\section{RESULTADOS}

Apresentam-se três indicadores de desempenho que estão sendo monitorados após implementadas as melhorias propostas, os quais indicam ter havido incremento no desempenho do processo, considerando como referência o ano de 2014 em que o processo antigo era ainda utilizado.

As informações enviadas aos coordenadores de curso se mostraram efetivas para diminuir o número de consultas por e-mail feita pelos coordenadores, conforme Tabela 1. Nela, encontra-se também o número de alunos que fizeram a consulta para sanar dúvidas sobre o programa. Enfim, foram sistematizados dados quanto ao número de dias necessários à divulgação do resultado da seleção. 
Tabela 1 - Indicadores de desempenho do macroprocesso PEE-AUGM: comparativo antes e após aplicação de melhorias

\begin{tabular}{ccccccc}
\hline Ano & $\begin{array}{c}\text { Número de consultas } \\
\text { de coordenadores de } \\
\text { Curso por e-mail }\end{array}$ & $\%$ & $\begin{array}{c}\text { Número de } \\
\text { consultas de } \\
\text { estudantes por } \\
\text { e-mail }\end{array}$ & $\begin{array}{c}\text { Dias para } \\
\text { divulgação do } \\
\text { resultado final }\end{array}$ & $\%$ \\
\hline $\mathbf{2 0 1 4}$ & 19 & $37 \%$ & 25 & $28 \%$ & 18 & $44 \%$ \\
$\mathbf{2 0 1 5}$ & 12 & 18 & 10 & $44 \%$ \\
$\mathbf{2 0 1 6}$ & 5 & $58 \%$ & 12 & $52 \%$ & 10 & \\
\hline
\end{tabular}

Fonte: Autores

Nota-se que no primeiro ano da implementação da melhoria, 2015, houve uma redução de $37 \%$ no número de consultas dos coordenadores sendo tal redução de $74 \%$ em 2016. Quanto à consulta dos estudantes, observou-se redução de $28 \%$ no primeiro ano e $52 \%$ no segundo.

A inclusão do poder decisório da SRInter na eventualidade de não haver selecionados para um determinado curso, adotada por ocasião da elaboração do edital, processo 5.1.2, reduz o desperdício da espera mitigando o risco de aguardar o período do ciclo de um novo edital. Adicionalmente, mitiga uma perda não considerada no estudo em função de não representar falha específica no processo que seria a frustração no âmbito do curso que não foi contemplado por desistência do aluno ou falta de suplente.

Tal situação é captada pelo indicador de "dias para a divulgação do resultado final". No primeiro ano houve redução de $44 \%$ no tempo de divulgação, para o segundo ano não houve redução em relação ao ano anterior tendo se mantido o mesmo percentual de redução em relação a 2014.

\section{CONCLUSÕES}

O trabalho aqui descrito foi pensado inicialmente como uma aplicação direta da mentalidade enxuta no Programa de Intercâmbio PEE-AUGM. Variáveis de contexto, entretanto, fizeram com que tanto os procedimentos de modelagem, quanto as técnicas utilizadas fossem adaptadas à situação. Ao final, as técnicas de modelagem e o processo de mapeamento utilizados na pesquisa foram, fortemente, determinados pelas limitações do ambiente de uso, especialmente relativas ao treinamento em modelagem de processos e à questão da comunicação dos modelos AS-IS e TO-BE aos stakeholders com vistas ao comprometimento desses atores 
com o processo proposto. Nesse sentido, foram utilizadas técnicas de produção enxuta conjugadas a métodos mais tradicionais de mapeamento e modelagem.

Observou-se que a abordagem de processos utilizando VSM, embora tenha sido contextualizada a ambientes de serviços e processos administrativos mediante o conceito de lean office, envolve complexidade considerável para seu uso demandando, como outras técnicas enxutas, treinamento para que seja usada com efetividade. Houve grande dificuldade da equipe de pesquisadores quanto ao uso da ferramenta, o que no início do trabalho estava dificultando a sistematização e a comunicação de melhorias a serem aplicadas ao processo, especialmente na discussão com os stakeholders envolvidos no trabalho. Utilizar os fluxogramas de processo como ponto de partida permitiu à equipe uma maior familiarização com as técnicas de mapeamento e melhoria de processos e isso, ao final, facilitou uma etapa posterior de elaboração do VSM.

Ao final, os processos administrativos necessários ao PEE-AUGM foram mapeados e utilizou-se a sistemática de analisar sistematicamente os desperdícios, conforme as teorias da mentalidade enxuta. Foram sugeridas e implantadas melhorias, corroborando com estudos que demonstram a eficácia da ME como forma de tornar mais produtivos processos administrativos. Conforme o Quadro 2, verificou-se como um dos mais frequentes desperdícios, o defeito relativo aos erros de documentação. Após análise dos processos sugeriu-se modificar documentos utilizados no Programa e eliminar atividades que geravam mais desperdício e não agregavam valor. Os resultados demonstraram graus de melhoria da ordem de $74 \%$ no fluxo de informações e de $44 \%$ na redução de tempos de processamento.

Não foi utilizado o VSM com os tempos relacionados porque não havia um controle gerencial estruturado de maneira que fosse possível levantar dados realistas de tempos de cada atividade ou processo. Os setores na Administração Pública são geridos por funções e não por processos, o que inviabiliza, ou dificulta sobremaneira, a aplicação de técnicas de BPM ou lean. Não abordar os tempos do processo fez com que o trabalho fosse direcionado à diminuição de operações que não agregavam valor e à racionalização do fluxo de informação, o que, por fim, permitiu que fossem consolidados indicadores de processo, conforme apresentado na seção 5.

Revista Produção Online. Florianópolis, SC, v.17, n. 2, p. 406-439, 2017. 
A literatura em ME não discute a questão da complexidade do VSM de uma maneira direta, mas as pesquisas têm demonstrado que a ME não tem atingido resultados tão significativos como esperado em função de problemas que podem estar relacionados com o treinamento dos envolvidos nas técnicas a ela relacionadas e ao caráter neo-taylorista das aplicações de ME no Ocidente. Nesse sentido, com relação ao VSM, pode-se traçar uma hipótese a ser testada em pesquisas futuras, de que sua elaboração seja paulatina e utilize fluxogramas de processo como ponto de partida. Uma vez que tais fluxogramas são comuns no Brasil desde os anos 90, quando foram introduzidos juntamente a outras ferramentas de gestão da qualidade, essa técnica pode contribuir para a implantação da ME de uma maneira efetiva, similarmente ao caso aqui apresentado.

Entre a última década do século passado e a primeira deste, havia expectativa crescente de cientistas e consultores de organizações quanto a uma migração de uma abordagem funcional para uma abordagem processual na estruturação de empresas e organizações públicas. Mais de uma década depois, a organização por processos continua mais um ideal que uma realidade nas organizações em geral, especialmente no serviço público brasileiro. Como contribuição, em termos de aplicação de melhorias de processo, este artigo demonstra uma situação em que foi realizada pesquisa ação em um órgão público em que, dadas as características da burocracia utilizada e do perfil técnico e educacional do público, foi necessário compor técnicas de mapeamento baseadas em ferramentas de BPM, como fluxogramas de processo e SIPOC, com ferramentas de produção enxuta, especialmente a identificação de desperdícios. Os mapas de estado atual e futuro, no formato VSM demonstraram ser importantes para compilar os desperdícios do processo e visualizá-lo de uma maneira sistemática. Entretanto, verificou-se que os mesmos implicavam em dificuldades de comunicação e de discussão das possibilidades de melhoria junto aos stakeholders.

Ainda que a presente pesquisa possa servir para estudos futuros, os resultados não devem ser generalizados para as Universidades brasileiras. Primeiramente, porque mesmo sendo Instituições Públicas de ensino superior, cada uma delas tem estruturas administrativas próprias e maneiras distintas de gerenciar os processos inerentes aos intercâmbios. Apesar disso, o que se observou na 
discussão com os participantes do processo é que diversas outras ações desenvolvidas na Universidade seguem processos ad hoc muito similares ao aqui abordado, o que sugere que esse tipo de ação possa ser utilizado em outros contextos dentro do serviço público.

\section{AGRADECIMENTOS}

Os autores agradecem, com sinceridade, ao editor e aos revisores do texto. A contribuição dada ao trabalho final foi sine qua non, tanto no aspecto de conteúdo, quanto no de forma.

\section{REFERÊNCIAS}

ABDI, F.; SHAVARINI, S. K.; HOSEINI, S. M. S. GLean Lean: How to use Lean approach in service industries? Journal of Services Research, v. 6, p. 191-206, jul. 2006.

ALBUQUERQUE, J. P. Flexibilidade e modelagem de processos de negócio: uma relação multidimensional. Revista de Administração de Empresas, São Paulo, SP, v. 52, n. 3, p. 313-329, 2012. http://dx.doi.org/10.1590/S0034-75902012000300004

ASSOCIATION OF BUSINESS PROCESS MANAGEMENT PROFESSIONALS.Guia para o gerenciamento de processos de negócio: corpo comum de conhecimento (BPM CBOK). Versão 3.0. Chicago: Association of Business Process Management Professionals, 2013.

BARBALHO, S. C. M.; SILVA, S. L.; CUSTÓDIO, J. E. S. C.; DIAS, M. A. Aplicabilidade do gerenciamento da mudança de engenharia na tropicalização de um equipamento industrial. Revista Produção Online, v. 16, p. 743-753, 2016. http://dx.doi.org/10.14488/1676$\underline{1901 . v 16 i 2.2198}$

BARBALHO, S. C. M.; RICHTER, E. H.; ROZENFELD, H. Melhorando o processo de aquisição de materiais e componentes para protótipos de novos produtos. Revista Gestão Industrial, Ponta Grossa, v.4, n. 3. p. 22-33, 2008. DOI: 10.3895/S1808-

04482008000300002

CHAY, T. et al. Towards Lean transformation: the analysis of Lean implementation frameworks. Journal of Manufacturing Technology Management, v. 26, n. 7, p. 1031 1052, 2015. http://dx.doi.org/10.1108/JMTM-10-2013-0143

COUGHLAN, P.; COGHLAN, D. Action research for operations management. International Journal of Operations \& Production Management, v. 22, n. 2, p. 220-240, 2002. http://dx.doi.org/10.1108/01443570210417515

DAVENPORT, T. H. Reengenharia de Processo: como inovar na empresa através da tecnologia da informação. 5. ed. Rio de Janeiro: Campus, 1994. 
DANIELSSON, C. B. An explorative review of the Lean Office concept. Journal of Corporate Real Estate, v. 15, n. 3/4, p. 167-180, 2013. http://dx.doi.org/10.1108/JCRE-022013-0007

ENDLER, K. D. E.; BOURSCHEIDT, L. E.; SCARPIN, C. T.; STEINER, M. T. A.; GARBUIO, P. A. R. Lean Seis Sigma: uma contribuição bibliométrica dos últimos 15 anos. Produção Online, Florianópolis, SC, v.16, n. 2, p. 575-605, abr./jun. 2016.

http://dx.doi.org/10.14488/1676-1901.v16i2.2023

GODINHO FILHO, M.; FERNANDES, F. C. F. Manufatura enxuta: uma revisão que classifica e analisa os trabalhos apontando perspectivas de pesquisas futuras. Gestão e Produção, São Carlos, SP, v. 11, n. 1, p. 1-19, jan./abr. 2004. http://dx.doi.org/10.1590/S0104530X2004000100002.

GONÇALVES, J. E. L. Processo, Que Processo? Revista de Administração de Empresas, São Paulo, SP, v. 40, n. 4, p. 8-19, out./dez. 2000a. http://dx.doi.org/10.12660/gvexec.v1n1.2002.34758

As empresas são grandes coleções de processos. Revista de Administração de Empresas, v. 40, n.1, p. 6-19, jan./mar., 2000b. http://dx.doi.org/10.1590/S0034$\underline{75902000000100002}$

GREEF, A. C.; FREITAS, M. C. D.; ROMANEL, F. B. Lean Office: Operação, gerenciamento e Tecnologias. São Paulo: Atlas, 2012.

HINES, P.; TAYLOR, D. Going Lean: a guide to implementation. Cardiff: Lean Enterprise Research Center, 2000.

LEITE, H. R.; VIEIRA, G. E. Lean philosophy and its applications in the service industry: a review of the current knowledge. Production, São Paulo, SP, v. 25, n. 3, p. 529-541, 2015. http://dx.doi.org/10.1590/0103-6513.079012

KRAJEWSKI, L.; RITZMAN, L.; MALHOTRA, M. Administração de Produção e Operações.São Paulo: Pearson Prentice Hall, 2009

KLUSKA, R. A.; LIMA, E. P; COSTA, S. E. G. Uma proposta de estrutura e utilização do gerenciamento de processos de negócio. Produção On-line, Florianópolis, SC, v. 15, n. 3, p. 886-913, jul./set. 2015. http://dx.doi.org/10.14488/1676-1901.v15i3.1867

MILAN, G. S.; VERSETTI, R. Melhorias em processos com impacto na eficiência operacional: um estudo ambientado em um laboratório de análises clínicas. Produção Online, Florianópolis, SC, v.12, n. 4, p. 1031-1056, 2012. http://dx.doi.org/10.14488/16761901.v12i4.1004

MÜLLER, G. L.; DIESEL, L.; SELLITTO, M. A. Análise de processos e oportunidades de melhorias em uma empresa de serviços. Produção Online, Florianópolis, SC, v. 10, n. 3, p. 524-550, set. 2010. http://dx.doi.org/10.14488/1676-1901.v10i3.241

MÜCKENBERGER, E. et al. Gestão de processos aplicada à realização de convênios internacionais bilaterais em uma instituição de ensino superior pública brasileira. Revista Produção, São Paulo, SP, v. 23, n. 3, p. 637-651, 2013. http://dx.doi.org/10.1590/S0103$\underline{65132012005000076}$ 
OHNO, T. Toyota Production System: beyond large-scale production. Florida, Taylor \& Francis Group, 1988.

PIERCY, N.; RICH, N. Lean transformation in the pure service environment: the case of the call service centre. International Journal of Operations \& Production Management. v. 29, n. 1, p. 54-76, 2009. http://dx.doi.org/10.1108/01443570910925361

PINHEIRO, T. H.; SCHELLER, A.C.; CAUCHICK MIGUEL, P. A. Integração do seis sigma com o lean production: uma análise por meio de múltiplos casos. Revista Produção Online, v. 13, p. 1297-1324, 2013. http://dx.doi.org/10.14488/1676-1901.v13i4.1291

SALGADO, E. G. et al. Análise da aplicação do mapeamento do fluxo de valor na identificação de desperdícios do processo de desenvolvimento de produtos. Gestão e Produção, São Carlos, SP, v. 16, n. 3, p. 344-356, jul./set. 2009. http://dx.doi.org/10.1590/S0104-530X2009000300003

SANTOS, L. C.; VARVAKIS, G. Projeto e análise de processos de serviços: uma avaliação de técnicas de representação. Produto e Produção, Porto Alegre, RS, v. 5, n. 3, p. 01-16, out. 2001.

SAURIN, T. A.; RIBEIRO, J. L. D.; MARODIN, G. A. Identificação de oportunidades de pesquisa a partir de um levantamento da implantação da produção enxuta em empresas do Brasil e do exterior. Gestão e Produção, São Carlos, SP, v. 17, n. 4, p. 829-841, 2010. http://dx.doi.org/10.1590/S0104-530X2010000400015

SCHELLER, A.C.; CAUCHICK MIGUEL, P. A. Adoção do seis sigma e lean production em uma empresa de manufatura. Revista Produção Online, v. 14, p. 1316-1347, 2014. http://dx.doi.org/10.14488/1676-1901.v14i4.1652

SELLITTO, M. A.; BORCHARDT, M.; PEREIRA, G. M. Presença dos princípios da mentalidade enxuta e como introduzí-los nas práticas de gestão das empresas de transporte coletivo de Porto Alegre. Revista Produção, São Paulo, SP, v. 20, n. 1, p. 15-29, 2010. http://dx.doi.org/10.1590/S0103-65132010005000009

SERAPHIM, E. C.; SILVA, I. B.; AGOSTINHO, O. L. Lean Office em organizações militares de saúde: estudo de caso do posto médico da guarnição militar de Campinas. Gestão e Produção, São Carlos, v. 17, n. 2, p.389-405, 2010. http://dx.doi.org/10.1590/S0104530X2010000200013

SHOOK, J.; ROTHER, M. Aprendendo a enxergar: mapeando o fluxo de valor para agregar valor e eliminar o desperdício. Ed. Lean Institute Brasil, 2012.

SILVA, F. P. C.; PEREIRA, N. A. Modelagem de processos de negócios na implementação de ERPs nacionais em PMEs. Revista Produção, São Paulo, SP, v. 16, n. 2, p. 341-352, 2006. http://dx.doi.org/10.1590/S0103-65132006000200013

TAPPING, D.; SHUKER, T. Lean Office: Gerenciamento do fluxo de valor para áreas administrativas. São Paulo: Leopardo, 2010.

TEGNER, M. G. et al. Lean Office e BPM: proposição e aplicação de método para a redução de desperdícios em áreas administrativas. Produção On-line, Florianópolis, SC, v. 16, n. 3, p. 1007-1032, jul./set. 2016. http://dx.doi.org/10.14488/1676-1901.v16i3.2308 
TELES, A. C. T. O. Internacionalização acadêmica: um percurso de desafios. Revista da Universidade Federal de Goias, v. 7, n. 2, p.300-320, 2005.

THIOLLENT, M. Pesquisa-ação nas organizações. São Paulo/SP: Editora Atlas, 1997. WALTER, O. M. F. C.; TUBINO, D. F. Métodos de avaliação da implantação da manufatura enxuta: Uma revisão da literatura e classificação. Gestão e Produção, São Carlos, SP, v. 20, n. 1, p. 23-45, 2013. http://dx.doi.org/10.1590/S0104-530X2013000100003

WOMACK, J. P.; JONES, D. T. Lean thinking: banish waste and create wealth in your corporation. New York: Free Press, 2003.

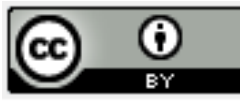

Artigo recebido em 07/01/2016 e aceito para publicação em 06/04/2017 DOI: http://dx.doi.org/10.14488/1676-1901.v17i2.2314 